\title{
THINKING, INTELLECT AND MATHEMATICS TRAINING
}

\section{DiAnA R. STEFANOVA}

ABSTRACT: In this article we suggest some tools for development of students' thinking and intellect using different ways of learning mathematics. We have considered a learning approach that stimulates the intellectual development of learners, namely tasks, that take qualities such as wits, flexibility, transfer of knowledge in new conditions etc, when solving the questions.

KEYWORDS: thinking, intellect, activation

2020 Math. Subject Classification: $97 D 50$ and 97D60, $97 G 40$

\section{МИСЛЕНЕ, ИНТЕЛЕКТ И ОБУЧЕНИЕТО ПО МАТЕМАТИКА}

\section{ДИАНА Р. СТЕФАНОВА}

Непрекъснатото развитие на науката и техниката издига пред училището една от главните задачи на развитие на обществото, а именно възпитаване младите хора в активна мисловна дейност. По проблема за мисленето са писали редица автори $[14,3,5]$. Освен това е изяснено и видовете мислене и редица операции свързани с него като: сравнение, анализ, синтез, абстрахиране и обобщение [7].

В научната литература се изяснява и творческото мислене $[13,8,15]$. Тук ще отбележим, че понятие, близко по значение на мисленето, е интелектът. Посочва се, че двата термина изразяват „различни страни на едно и също явление“ [4], т.е те са много близки една до друга в самата им същност и отразяват различните 
Stefanova D.

страни на една обща концепция. Интелектьт е способността на човека да осъзнава мисленето, а то е самият процес на възприятие, реакция и разбиране. Все пак има разлика: мисленето е характерно за всеки човек, докато това твърдение не важи за интелекта [2, 17]. Ще отбележим, че мисленето и интелекта се явяват отличителна черта на човека, като интелектът е по-широко понятие от мисленето [4].

Учените не дават единно определение на понятието интелект. В науката може да се каже, че съществуват две от найразпространените му определения, а именно:

$>\quad$ интелект - способност да се адаптира към средата;

$>$ интелект - способност да се решават умствено задачи.

Редица психолози отбелязват, че интелекта има сложна структура, за което са писали [1] и други. Споровете за структурата на интелекта не са случайни. Те представляват не само научен интерес, но и помагат да отговорим на въпрос, който вълнува всички: от какви фактори зависи развитието на интелекта. Днес учените имат сходно мнение, че развитието му зависи както от вродените фактори, така от възпитанието, обучението и обкръжаващата среда.

В повечето дефиниции в основата на интелекта стои способността за решаване на задачи или ситуации с помощта на мисленето. Към интелектуалните способности се отнасят бързината на разбирането, лекотата при боравене с числа, концентрацията и превключването на вниманието, мисловните операции - анализ, синтез, сравнение, абстрахиране и обобщение, качествата на мисловната дейност - бързина, гъвкавост, самостоятелност, както и видовете мислене - абстрактно логическо, техническо и нагледно - образно. Освен вниманието и мисленето, неразделна част на интелекта е и паметта - запомняне, съхраняване и възпроизвеждане на о пределена информация. Обемът на паметта, бързината на запомняне, трайността на съхраняване, точността и услужливостта на паметта са сьществени признаци при неговите прояви. 
Реалният успех на човека в училище, по време на следването и в професията до голяма степен зависят от неговия интелект. Като негов индикатор е мисленето със специфичните мисловни операции и качества на ума. Интелектуалната дейност е процес, в който има следните фази на мислене - ориентиране в условията на задачата, изграждане на план за действие, изпълнение на набелязания план за решаване на задачата и накрая сравняване и сверяване на получения резултат с предварително набелязаната цел.

Сред моделите на интелекта се счита, че най-известен е „кубическия модел на интелекта на Д. Гилфорд“, при който разузнаването се описва от три категории [4] (фиг. 1):

$>$ съдържание - за какво мислим;

$>$ операции - как мислим за него;

$>$ резултати - това, което получаваме в резултат на умствената дейност. От това виждаме, че съотношението на мисленето и разума е много близко, интелектът е изграден върху способността на човека да мисли. И ако продуктивното мислене дава резултати, тогава може да се говори за разузнаване.

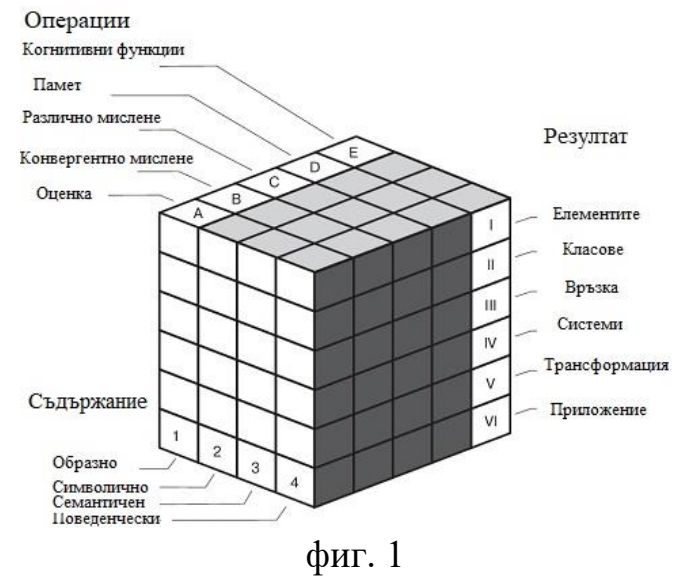


В публикациите [9] са изяснени проблемът за развитието на интелекта и начините за развитието му в обучението по математика. Посочено е и какви задачи поставя този проблем. „Формирането и развитието на интелектуалните качества на ученика при обучението по математика (гъвкавост, рационалност, широта,...., критичност и самокритичност, самостоятелност и т.н.) става предимно чрез дейността решаване на математически задачи“ [1]. Затова много важно е какви задачи ще се включат към различни теми от училищния курс по математика, за да активизират и развият тези качества на ученика [11].

В настоящата разработка нямаме за цел да изясняваме изследванията и мненията на различни автори на това понятие. Ние приемаме, че за развитието на интелекта допринася способността на човек да решава задачи в нова среда, т.е. получените знания се използват за решаване на задачи в нови условия и да се потърсят пътища за решаването на различни проблеми.

В своята работа сме търсили такива теми от училищния курс по математика, които могат да се приложат в разнообразна нова среда. Учебното съдържание, което използвахме е свързано с темата „Прогресии“. За целта предлагаме една система от задачи, в които знанията за прогресии се прилагат в друга среда различна от стандартната.

I група: Задачи, при които прогресията явно е дадена в условието им.

Задача 1. Височината $C D$ на $\triangle A B C$ дели страната $A B$ на части $A D$ и $D B$ така, че дължините на отсечките $A D, C D$ и $D B$ са последователни членове на геометрична прогресия. Ако точка $M$ е средата на страната $A B$, да се докаже, че дължините на отсечките $A D, C M$ и $D B$ са последователни членове на аритметична прогресия и че точка $M$ е центърът на описаната около $\triangle A B C$ окръжност. 
Доказателство: Тук в условието на задачата е зададено, че $A D, C D$ и $D B$ са последователни членове на геометрична прогресия. Тогава записваме $C D^{2}=$ $A D . D B$, т.е. $\frac{C D}{A D}=\frac{D B}{C D}$. Това равенство показва,

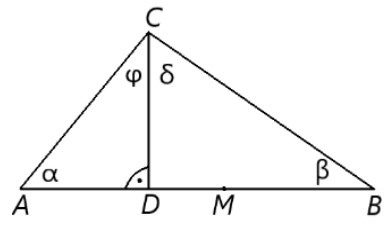

черт. 1 отношението на катетите на двата правоъгълни $\triangle A C D$ и $\triangle C D B$ са равни. Тогава тези триъгълници са подобни (черт. 1) и следователно $\alpha=\delta, \beta=\varphi$. От друга страна $\beta+\delta=\alpha+\varphi=90^{\circ}$. Тогава $\varphi+\delta=\varphi+\alpha=90^{\circ}$, т.е. $\triangle A B C$ е правоъгълен и средата $M$ на хипотенузата му $A B$ е центърът на описаната около него окръжност. По-нататък $A D+D B=A B=2 C M$, т.е. $C M=\frac{A D+D B}{2}$ и следователно $A D, C M$ и $D B$ са последователни членове на аритметична прогресия.

Задача 2. Страните на $\triangle A B C$ образуват аритметична прогресия. Лицето му се отнася към лицето на равностранен триъгълник със същия периметьр както 3:5. Намерете ьглите на $\triangle A B C$. Докажете, че $c^{2}-4 d^{2}=12 r^{2}$, където $c$ е средната по-големина страна на $\triangle$ $A B C, d$ е разликата на аритметичната прогресия като $d>0$ и $r$ е радиусът на вписаната в $\triangle A B C$ окръжност. (УНСС, 1992 г.)

Доказателство: Тъй като страните на $\triangle A B C$ образуват аритметична прогресия, нека ги означим по следния начин $B C=$ $c-d, A B=c, A C=c+d$. Тогава полупериметьрьт на $\triangle A B C$ е $p=\frac{3 c}{2}$ и лицето му е $S_{\triangle A B C}=p . r=\frac{3 c . r}{2}$. От друга страна можем да използваме и Хероновата формула за лице на триъгълник, т.е. $S_{\triangle A B C}=\sqrt{\frac{3 c}{2}\left(\frac{c}{2}+d\right) \frac{c}{2}\left(\frac{c}{2}-d\right)}=\frac{c \sqrt{3}}{4} \sqrt{c^{2}-4 d^{2}}$. Следователно $\frac{3 c . r}{2}=\frac{c \sqrt{3}}{4} \sqrt{c^{2}-4 d^{2}}$, откъдето непосредствено следва $c^{2}-4 d^{2}=12 r^{2}$. По-нататьк равностранният триъгълник със същия (както $\triangle A B C$ ) периметър $3 c$ има страна $c$ и лице $S=$ $\frac{c^{2} \sqrt{3}}{4}$. Тогава (по условие) $S_{\triangle A B C}=\frac{3}{5} \cdot \frac{c^{2} \sqrt{3}}{4}=\frac{3 c^{2} \sqrt{3}}{20}$. Но (от по-горе) 
$S_{\triangle A B C}=\frac{c \sqrt{3}}{4} \sqrt{c^{2}-4 d^{2}}$, така че $\frac{c \sqrt{3}}{4} \sqrt{c^{2}-4 d^{2}}=\frac{3 c^{2} \sqrt{3}}{20}$, откъдето след преобразуване получаваме $c=\frac{5 d}{2}$. Следователно $B C=$ $\frac{3 d}{2}, A B=\frac{5 d}{2}, A C=\frac{7 d}{2}$. Сега от косинусовата теорема намираме $\cos \Varangle B A C=\frac{13}{14}, \cos \Varangle A C B=\frac{11}{14}, \cos \Varangle A B C=-\frac{1}{2} \quad$ (така $\quad$ че $\left.\Varangle A B C=120^{\circ}\right)$.

Задача 3. Широчината и дължината на правоъгълен паралелепипед са съответно $2 \mathrm{~cm}$ и $4 \mathrm{~cm}$. Определете височината на паралелепипеда, ако лицата на три негови съседни стени образуват аритметична прогресия.

Решение: Нека означим височината на паралелепипеда $\mathrm{c} h \mathrm{~cm}$. След това пресмятаме лицата на трите различни стени на паралелепипеда (черт. 2) $S=2.4=8 \mathrm{~cm}^{2}$; $S=2 . h \mathrm{~cm}^{2}$; и $S=4 . h \mathrm{~cm}^{2}$. Тъй като в условието на задачата, не е посочено

в какъв ред лицата образуват аритметична прогресия, то ще трябва учениците да открият и трите възможни случаи:

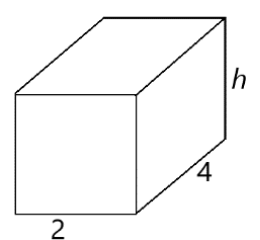

черт. 2

I случай: Когато $2 . h ; 4 . h$ и 8 образуват аритметична прогресия в този ред.

Използваме свойството на средния член на аритметичната прогресия и получаваме уравнението $2.4 . h=2 . h+8$, откъдето намираме, че $h=1 \frac{1}{3} \mathrm{~cm}$.

II случай: Когато $8 ; 2 . h$ и 4. $h$. образуват аритметична прогресия в този ред

Аналогично на решението на първия случай получаваме уравнението 2.2.h =8+4.h. В този случай задачата няма решение.

III случай: Когато $2 . h$; 8 и $4 . h$ образуват аритметична прогресия в този ред. 
Използвайки същото свойство както в първи и втори случай получаваме уравнението $2.8=2 . h+4 . h$, откъдето намираме, че $h=2 \frac{2}{3} \mathrm{~cm}$.

На базата на разгледаните случаи задачата има две решения: $h_{1}=$ $1 \frac{1}{3} \mathrm{~cm} ; h_{2}=2 \frac{2}{3} \mathrm{~cm}$.

Задача 4. Лицето на основата, лицето на околната повърхнина и лицето на пълната повърхнина на правилна триъгълна пирамида взети в този ред, образуват аритметична прогресия.

a) Да се намери големината на двустенния ьгъл, определен от околна стена и основата на пирамидата.

б) В пирамидата са вписани прави крьгови цилиндри така, че долната основа на всеки цилиндър лежи и в равнината на основата на пирамида, а горната му основа има точно по една обща точка с всяка от околната стени. Ако основният ръб на пирамидата има дължина $a$, да се намери радиусът на основата на този вписан в пирамидата прав крьгов цилиндър, който има най-голям обем. (ТУ-София, 2000 г.)

Доказателство: Нека пирамидата е $A B C D, A B=a, O \quad$ e ортогоналната проекция на върха $D$ върху основата $A B C$, М е средата на $B C, D M=k$ e апотемата на пирамидата и $\Varangle O M D=\varphi$ (черт. 3) е ъгъльт между околна стена и основата. Нека $B, S$ и $S_{1}=S+B$ са лицата съответно на основата, на околната повърхнина и на пълната повърхнина на пирамидата.

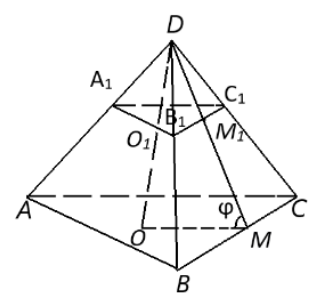

черт. 3

От условието, че лицата са членове на аритметична прогрсия имаме $2 S=S_{1}+B=2 B+S$ или $S=2 B$. Оттук следва $3 \frac{a k}{2}=$ $\frac{2 a^{2} \sqrt{3}}{4}$ или $k=\frac{a \sqrt{3}}{3}$.

a) От правоъгълния $\triangle D O M$ имаме $\cos \varphi=\frac{O M}{D M}$ и от $O M=$ $\frac{a \sqrt{3}}{6}, D M=k=\frac{a \sqrt{3}}{3}$ получаваме $\cos \varphi=\frac{1}{2}$. Следователно $\varphi=60^{\circ}$. 
б) Горната основа на всеки даден в условието цилиндър лежи в равнина, успоредна на равнината $A B C$ и сечението на такава равнина с пирамидата е равностранен $\triangle A_{1} B_{1} C_{1}\left(A_{1} \in D A, B_{1} \in\right.$ $\left.D B, C_{1} \in D C\right)$. Нека $\mathrm{O}_{1}$ е центърът на този триъгълник $\left(\left(\mathrm{O}_{1} \in D O\right)\right.$, a $\mathrm{M}_{1}$ е средата на $B_{1} C_{1}$. От даденото в условието следва, че горната основа на цилиндъра е вписана в $\triangle A_{1} B_{1} C_{1}$ окръжност с център $\mathrm{O}_{1}$ и радиус $\mathrm{O}_{1} \mathrm{M}_{1}$ и $0_{1}$ е оста на цилиндъра. Правоъгълните $\triangle$ $D O_{1} M_{1}$ и $\triangle D O M$ са подобни, в частност $\Varangle O_{1} M_{1} D=\Varangle O M D=60^{\circ}$. Нека $O_{1} M_{1}=x$. Последователно пресмятаме $O M=\frac{a \sqrt{3}}{6}, D O=$ $O M=\sqrt{3}=\frac{a}{2}, \quad D O_{1}=O_{1} M_{1} \sqrt{3}=x \sqrt{3}, O O_{1}=D O-D O_{1}=\frac{a}{2}-$ $x \sqrt{3}$.

Обемът на цилиндъра е $V=\pi O_{1} M_{1}^{2} .0 O_{1}=\pi x^{2}\left(\frac{a}{2}-\right.$ $x \sqrt{3})=\frac{\pi}{2}\left(-2 \sqrt{3} x^{3}+a x^{2}\right)$. От $O_{1} M_{1}<O M$ следва $x \in\left(0 ; \frac{a \sqrt{3}}{6}\right)$, при това $x$ може да приема всяка стойност от този интервал. Накрая по стандартния начин установяваме, че функцията $f(x)=$ $-2 \sqrt{3} x^{3}+a x^{2}$ расте в интервала $\left(0 ; \frac{a \sqrt{3}}{9}\right)$ и намалява в $\left(\frac{a \sqrt{3}}{9} ; \frac{a \sqrt{3}}{6}\right)$ и следователно най-голямата ѝ стойност в интервала $\left(0 ; \frac{a \sqrt{3}}{6}\right)$ се достига при $x=\frac{a \sqrt{3}}{9}$. Така търсеният радиус на основата на цилиндъра с най-голям обем е равен на $\frac{a \sqrt{3}}{9}$.

Задача 5. Намерете трицифрено число, което се дели на 45 и цифрите му образуват аритметична прогресия.

Решение: Нека $x$ е цифрата на стотиците, $y$ е цифра на десетиците и $z$ е цифрата на единиците. Тъй като $x, y, z$ са членове на аритметична прогресия, то $2 y=x+z$ (1). Търсено число има вида $100 x+10 y+z$, но то по условие трябва да се дели на 45 , т.е. ще има вида $100 x+10 y+z=45 p$ (2). Тогава исканото число се определя от условията (1) и (2). За цифрата на единиците имаме две възможности $z=0$ или $z=5$, тъй като това са условията, за да 
се дели на 5 числото. Разглеждаме случай когато $z=0$, тогава от (1) получаваме, че $x=2 y$, а от (2) намираме $100 x+10 y=45 p$, или $20 x+2 y=9 p, 20 x+\mathrm{x}=9 p$ или $7 x=3 p$. Това означава, че $x$ се дели на 3 , но $x=2 y$ което означава, че $x$ е четно число. Но единствено четно, което се дели на 3 е числото 6 , тогава $y=3$ и исканото число е 630. Да разгледаме втория случай, при който $z=$ 5 , тогава условията от (1) и (2) приемат вида: $2 y=x+5$ и $100 x+$ $10 y+5=45 p$. Последното равенство преобразуваме във вида $20 x+2 y+1=9 p$ и по-нататьк от равенството $2 y=x+5$ получаваме $21 x+6=9 p$ или $7 x+2=3 p$. Последното равенство е възможно при $x=1,4,7$. Но тъй като $x+5$ е четно число $(2 y=$ $x+5)$, то за $x$ остават две възможностти: $x=1$ или $x=7$. В първия случай когато $x=1 y=3$, а във втория случай когато $x=$ $7, y=6$. Тогава търсените числа са 135 и 765. Окончателно търсените числа са 135, 630 и 765.

II група: Задачи, при които прогресиите не са дадени в условието, а трябва да се открият и да се използват в решението им.

Задача 5. Ако е дадена функцията $f(x)=5^{x}$, то решете уравнението $5 f(x)-1=24(f(0)+f(2)+f(4)+f(6)+f(8)+$ $f(10))$.

Решение: Пресмятаме последователно $f(0)=1, f(2)=5^{2}, f(4)=$ $5^{4}, f(6)=5^{6}, f(8)=5^{8}, f(10)=5^{10}$. Тогава даденото уравнение е равносилно на $5.5^{\mathrm{x}}-1=24\left(1+5^{2}+5^{4}+5^{6}+5^{8}+5^{10}\right)$. Лесно се установява, че числата $1,5^{2}, 5^{4}, 5^{6}, 5^{8}, 5^{10}$ образуват геометрична прогресия с първи член $\mathrm{a}_{1}=1$, частно $q=5^{2}$ и сумата им е $S_{6}=1 \cdot \frac{\left(5^{2}\right)^{6}-1}{5^{2}-1}=\frac{5^{12}-1}{24}$. От уравнението $5.5^{\mathrm{x}}-1=$ 24. $\frac{5^{12}-1}{24}$ намираме, че $x=11$.

Задача 6. Да се реши системата $\mid \begin{aligned} & x^{2}+x y+y^{2}=37 \\ & x^{2}+x z+z^{2}=28 \\ & y^{2}+y z+z^{2}=19\end{aligned}$. 
Решение: Не е трудно да видим, че $x \neq y, y \neq z$ и $x \neq z$ [16]. Например, ако $x=y$, то второто уравнение на дадената система ще е в противоречие с третото. В такъв случай дадената система е равносилна на системата $\mid \begin{aligned} & x^{3}-y^{3}=37(x-y) \\ & z^{3}-x^{3}=28(z-x) \\ & y^{3}-z^{3}=19(y-z)\end{aligned}$

Ако съберем почленно левите и десните страни на уравненията от системата (1) получаваме $37 x-37 y+28 z-28 x+19 y-19 z=0$, откъдето следва $x+z=2 y$. В $x+z=2 y$ може да забележим, че променливите $x, y$ и $z$ образуват аритметична прогресия, разликата на която е равна на $d$, където $d \neq 0$. В такъв случай $x=y-d \quad$ и $z=y+d$. Ще заместим $x=y-d \quad$ и $z=y+d$ в първото и третото уравнение на дадената система и получаваме $\mid$\begin{tabular}{l|l}
$(y-d)^{2}+y(y-d)+y^{2}=37$ \\
$y^{2}+y(y+d)+(y+d)^{2}=19$
\end{tabular} или $\quad \begin{aligned} & 3 y^{2}-3 y d+d^{2}=37 \\
& 3 y^{2}+3 y d+d^{2}=19\end{aligned}$. Ако от първото уравнение извадим второто, то получаваме $y d=-3$ и $\mid \begin{aligned} & y d=-3 \\ & 3 y^{2}+d^{2}=28\end{aligned}$, $3 y^{2}+\frac{9}{y^{2}}=28 \Rightarrow 3 y^{4}-28 y^{2}+9=0$. Корените на биквадратното уравнение са $y^{2}=9, y^{2}=\frac{1}{3}$ и като използваме, че $y d=-3$ намираме $\mid$\begin{tabular}{l|l|l}
$y_{1}=3$ \\
$d_{1}=-1$
\end{tabular},$\quad \begin{aligned} & y_{2}=-3 \\
& d_{2}=1\end{aligned}, \quad \begin{aligned} & y_{3}=\frac{1}{\sqrt{3}} \\
& d_{3}=-3 \sqrt{3}\end{aligned} \quad \begin{aligned} & y_{4}=-\frac{1}{\sqrt{3}} \\
& d_{3}=3 \sqrt{3}\end{aligned}$ След това 
заместваме в $x=y-d$ и $z=y+d$ и намираме решенията на дадената система $\left|\begin{array}{l|l|l|l}x_{1}=4 & x_{2}=-4 & x_{3}=\frac{10 \sqrt{3}}{3} & x_{4}=-\frac{10 \sqrt{3}}{3} \\ y_{1}=3, & y_{2}=-3, & y_{3}=\frac{\sqrt{3}}{3} \\ z_{1}=2 & z_{2}=-2 & \text { и } & y_{4}=-\frac{\sqrt{3}}{3} \\ z_{3}=-\frac{8 \sqrt{3}}{3}\end{array}\right| \begin{gathered}z_{4}=\frac{8 \sqrt{3}}{3}\end{gathered}$.

Задача 7. Иво подрежда пъзел, като всеки ден подрежда с $k$ елемента повече, отколкото предния. На дванадесетия ден той подредил два пьти по-малко елементи отколкото през първите 5 дни, взети заедно. На четиринадесетия ден Иво подредил 85 елемента. От колко елемента се състои пъзелът, ако Иво успял да го подреди на шестнадесетия ден, подреждайки с $k$ елемента повече отколкото на петнадесетия ден? (ДЗИ, 2011 г.)

Решение: Всеки ден Иво подрежда с $k$ елемента повече отколкото предходния. От това следва, че числата, определящи броя на подредените елементи през конкретния ден, образуват аритметична прогресия с разлика $d=k(k \in N)$. Означаваме с $a_{1}, a_{2}, a_{3} \ldots a_{16}$ членовете на тази прогресия, като $S_{5}=2 a_{12}$ (на 12 ден Иво е подредил два пъти по-малко елементи отколкото през първите 5 дни, взети заедно) и $a_{14}=85$ (на 14 ден Иво подредил 85 елемента). От $S_{5}=2 a_{12} \Leftrightarrow \frac{2 a_{1}+4 k}{2} .5=2\left(a_{1}+11 k\right) \Leftrightarrow a_{1}=4 k$ и от $a_{14}=85$ определяме, че $k=5$. След това намираме и $a_{1}=20$. Тогава броят на елементите, от които се състои пъзелът, е: $a_{1}+a_{2}+a_{3}+a_{16}=S_{16}=\frac{2 a_{1}+15 k}{2} \cdot 16=920$.

Задача 8. Група младежи решили да изпратят писма по Интернет с пожелания за късмет. Първия ден всеки от тях изпратил 
пожелания на петима свои приятели. Втория ден всеки от получилите пожеланието го препратил на други петима свои приятели и т.н., като всеки, получил пожелание предния ден, препращал пожеланието на петима свои приятели следващия ден. При тези условия в края на петия ден броят на изпратените пожелания бил 12500. Колко са младежите от групата, започнали инициативата? (ДЗИ, 2012 г.)

Решение: Нека броят на младежите е $n(n \in N)$. Тогава броят на изпратените през първия ден писма е $a_{1}=5 n$, през втория ден е $a_{2}=5 a_{1}$ и т.н. Числата $a_{1}, a_{2}, a_{3}, a_{4}, a_{5}$ образуват геометрична прогресия с частно $q=5$. По условие $a_{5}=12500 \Leftrightarrow a_{1} q=12500 \Leftrightarrow 5 n \cdot 5^{4}=12500 \Leftrightarrow n=4$. Следователно младежите от групата, започнали инициативата, са 4.

Задача 9. В равностранен триъгълник със страна $a$, е вписан кръг. След това в този триъгълник са вписани още три кръга, допиращи се до първия кръг и страните на триъгълника и още три кръга, допиращи се до вторите крьгове и страните на триъгљника и т.н. Да се намери сумата от лицата на всички вписани кръгове. (ВВВУ, 1984 г.) [12].

Решение: Радиусът на вписания в равностранния триъгљлник кръг е $R_{0}=\frac{a \sqrt{3}}{6}$. Ако построите допирателните на този кръг, успоредни на страните на триъгълника те отсичат от последния три равностранни триъгълника с една и съща страна $a_{1}=\frac{a}{3}$. Следващите три кръга са вписани в тези триъгълници и имат един и същи радиус $R_{1}=\frac{a_{1} \sqrt{3}}{6}=\frac{a \sqrt{3}}{18}$. Следващите три крьга са 
вписани в тези триъгълници и имат един и същи радиус $R_{2}=\frac{a \sqrt{3}}{54}$ и т.н. Сумата от лицата на всички вписани крьгове е $S=S_{0}+3\left(S_{1}+S_{2}+\ldots\right)=\pi R_{0}^{2}+3\left(\pi R_{1}^{2}+\pi R_{2}^{2}+\ldots\right)=\frac{11}{96} \pi a^{2}$.

Задача 10. Пресметнете сумата $2+22+222+\ldots+22 \ldots 2$. $n$-цифри

Решение: Нека дадената сума преобразуваме по следния начин: $2+22+222+\ldots+22 \ldots 2=2\left[1+(1+10)+\left(1+10+10^{2}\right)+\ldots+\right.$ $\left.\left(1+10+10^{2}+\ldots+10^{n-1}\right)\right]=2\left[S_{1}+S_{2}+S_{3}+\ldots+S_{n}\right]$, където $S_{k}-\mathrm{e}$ сумата на $k$ членовете на геометрична прогресия $1,10,10^{2}, \ldots(k=1,2, \ldots n)$. Като използваме формулата $S_{k}=\frac{b_{1}\left(q^{k}-1\right)}{q-1}$ за сумата на членовете на геометрична прогресия, получаваме

$$
\begin{aligned}
& 2\left[S_{1}+S_{2}+S_{3}+\ldots+S_{n}\right]=\left(\frac{10-1}{9}+\frac{10^{2}-1}{9}+\frac{10^{3}-1}{9}+\ldots+\frac{10^{n}-1}{9}\right)= \\
& \quad=\frac{2}{9}\left[10\left(1+10+10^{2}+\ldots+10^{n-1}\right)-n\right]= \\
& \frac{2}{9}\left[\frac{10\left(10^{n}-1\right)}{9}-n\right]=\frac{2\left(10^{n+1}-10-9 n\right)}{81} .
\end{aligned}
$$

За разлика от стандартните задачи, предложените от нас, изискват при решаването им проява на такива интелектуални качества като съобразителност, гъвкавост, пренос на знания в нови условия и т.н. Като заключение ще посочим, че за развитието на интелекта допринася владеенето на мисловните операции (анализ, 
синтез, сравнение, абстрахиране и обобщение и т.н), подбор на разнообразни видове задачи (задачи с пренос на знания, задачи решавани по различни начини и т.н.) [10].

Ефективни средства за развитието на мисленето и интелекта на учениците е използването на различни начини на обучение по математика. Освен това сме се стремили да научим учениците да обобщават и систематизират придобитите знания; да могат да осъществяват вътрешнопредметни и междупредметни връзки; самостоятелно да придобиват знания; да се приучават към изследователска работа; да превръщат обучението в творчески процес.

\section{ЛИТЕРАТУРА:}

[1] Айзенк, Г. Ю. (1995). Интеллект: новый взгляд, Вопросы психологии. № 1. С. 111-131.

[2] Александров, П., (1990). Интелект и обучение, Народна просвета, София

[3] Аристова, Л. П. (1968). Активность учения школьников, Москва: Педагогика, 131-141

[4] Баданина, Л., (2012). Психология познавательных процессов, Флинта, Москва, ISBN 978-5-9765-0226-0

[5] Гроздев, С., В. Ненков, Св. Дойчев. За високи постижения в математиката (в помощ на учителя) (2012). София: „Фондация Миню Балкански“ \& „Фондация Америка за България“", ISBN 978954-92830-3-7

[6] Кликс, Ф. (1983). Пробуждающееся мышление, У истоков человеческого интеллекта, Москва, „Прогресс“

[7] Маврова, Р., \& Бойкина, (2009). Средства за активизиране мисленето на учениците при обучението по математика, ПУ „Паисий Хилендарски“, Научни трудове, 46, 49-57 
[8] Маврова, Р., (2006). За интелектуалните качества на учениците при обучението по математика, ПУ „Паисий Хилендарски“, Научни трудове, 43, кн. 2, 15-22

[9] Mavrova, R., \& Boikina, D. (2005) Intellect and Directions for Intellectual Development of Students in the Education in Mathematics. International, Conference on Mathematics Education 3-5 June 2005, Svishtov-Bulgaria, Sofia, p. 357-361, ISBN 954-8880-21-0

[10] Павлова, Н., \& Харизанов, Кр., (2015). Технологии за описание на урок в обучението по математика, информатика и информационни технологии, УИ "Епископ Константин Преславски", ISBN 978-619201-052-2, Шумен

[11] Павлова, Н., (2016). Методическа и технологична реализация на дидактическо проектиране в обучението по математика, Математика и информатика, 59, 2, 204-214

[12] Паскалев, Г., (1987). Конкурсни задачи по математика за постъпване във ВУЗ, Наука и изкуство, София

[13] Пирьов, Г., (2000). Проблеми на когнитивната психология, Учене, мислене, интелигентност, АИ „Проф. Марин Дринов“, София, ISBN 954430715

[14] Рубинщайн, С., (1958). О мышлении и путях его исследовании, AHCCCP

[15] Рубинщайн, С. (1996). Основы общей психологии. СПб: Питер Ком

[16] Супрун, В., (2008). Математика для старшеклассников, Либраком, ISBN 978-5-397-00050-5

[17] Холодная, М., (2019). Психология интеллекта: парадоксы исследования, Москва, Юрайт, ISBN 978-5-534-07365-2

\section{Диана Р. Стефанова}

ОУ „Никола Вапцаров“, гр. Асеновград

e-mail: dianastefanova13@gmail.com 